\title{
Posterior chamber intraocular lenses at the Wilmer Institute: a comparative analysis of complications and visual results*
}

\author{
WARREN R. FAGADAU, A. EDWARD MAUMENEE, \\ WALTER J. STARK, $\mathbf{J}_{\mathbf{R}}$, AND MANUEL DATILES
}

From the Wilmer Ophthalmological Institute, Baltimore, Maryland, USA

SUMmARY Intraocular lens (IOL) implantation is now accepted as the most effective means of aphakic correction in selected patients undergoing cataract surgery. In terms of final rehabilitation, however, complications such as corneal oedema, retinal detachment, and cystoid macular oedema remain problematic. Results of prospective concurrent trials of IOL implantation performed at the Wilmer Institute are presented, with particular reference to the posterior chamber intraocular lens and with specific emphasis on postoperative complications.

As the second leading cause of blindness in the United States cataract constitutes an important public health problem. ${ }^{1}$ Increasingly sophisticated modes of operative instrumentation, along with earlier and more effective visual rehabilitation, have served to stimulate an increase in the rate of cataract surgery: of 640000 cataract operations performed in the United States in 1982 over $70 \%$ were associated with intraocular lens implantation..$^{2-4}$ In the most recent 6month interval of the FDA study the posterior chamber lens accounted for $48 \%$ of all intraocular lenses implanted and the anterior chamber lens, $45 \% .^{4}$ The purpose of this report is to present our personal experience with posterior chamber intraocular lens implantation, particularly with reference to postoperative complications such as corneal oedema, retinal detachment, and cystoid macular oedema. Results have been evaluated in the context of the broader Wilmer intraocular lens experience, comparing current methods with previously utilised techniques.

\section{Materials and methods}

One thousand and forty-one posterior chamber lenses have been implanted since August 1979 by 2 surgeons

* Presented in part at the annual meeting of the American Ophthalmologic Society in May 1983.

Correspondence to A. Edward Maumenee, MD, Wilmer Ophthalmological Institute, Johns Hopkins Medical Institutions. 601 North Wolfe Street, Baltimore, Maryland 21205, USA.
(A.E.M. and W.J.S.), using similar techniques. Extracapsular cataract extraction by means of nuclear expression and cortical irrigation/aspiration (KelmanCavitron unit) has been combined with the placement of a (Kratz-modified) Shearing-style posterior chamber lens, with $10^{\circ}$ angled loops, in the ciliary sulcus. All IOLs were soaked in balanced salt solution or aqueous dexamethasone phosphate for 15 minutes and then inspected under the operating microscope prior to implantation. All lenses were inserted with air or sodium hyaluronate (after January 1982) present in the anterior chamber, so as to protect the endothelial surface. Prior to August 1979 Binkhorst 4-loop iris-clip lenses were inserted, associated with intracapsular cataract extraction using techniques previously described. ${ }^{5}$

The patients were followed up in a prospective, concurrent manner, with careful documentation of postoperative visual acuities and complications. 'Persistent iritis' was defined as present in any eye requiring continuing steroid therapy to suppress intraocular inflammation. 'Clinical cystoid macular oedema' was defined as a reduction in prior distance and/or near visual acuity of 1 line or more on the Snellen chart, associated with ophthalmoscopic or fluorescein angiographic evidence of cystoid macular oedema. Eyes with 20/20 distance vision, Jaeger-one near vision, and a normal-appearing macula were not routinely subjected to angiographic examination. Mean visual acuity results have been calculated from a $\log$ scale of Snellen visual acuity followed by reconversion to the Snellen notation. 
Table 1 Intraocular lenses: experience at the Wilmer Institute.

\begin{tabular}{|c|c|c|c|}
\hline & Group I & Group II & Group III \\
\hline Total: & $\begin{array}{l}\text { 4-Loop } \\
\text { ICCE } \\
\text { Wet pack* } \\
200 \text { eyes }\end{array}$ & $\begin{array}{l}\text { 4-Loop } \\
\text { ICCE } \\
\text { Dry pack } \dagger \\
\text { 103 eyes }\end{array}$ & $\begin{array}{l}\text { Post. chamber } \\
\text { ECCE } \\
\text { Dry pack } \\
1041 \text { eyes }\end{array}$ \\
\hline $\begin{array}{l}\text { Dates of use } \\
\text { Patient age (yr) } \\
\text { Follow-up (mo) }\end{array}$ & $\begin{array}{l}\text { Jan 1975-Dec } 1977 \\
71(55-94) \\
54(12-95)\end{array}$ & $\begin{array}{l}\text { Jan 1978-Jul } 1979 \\
72(60-90) \\
25(12-70)\end{array}$ & $\begin{array}{l}\text { Aug 1979-Feb } 1983 \\
71(46-93) \\
12(3-44)\end{array}$ \\
\hline
\end{tabular}

*'Wet pack' IOLs, sterilised with $\mathrm{NaOH}$ solution.

†'Dry pack' IOLs, sterilised with ethylene oxide.

$\mathrm{ICCE}=$ intracapsular cataract extraction; ECCE =extracapsular extraction.

To compare results we have divided our cases into 3 groups (Table 1). Group I comprised those eyes receiving Morcher-manufactured (European) 4-loop Binkhorst IOLs sterilised by the sodium hydroxide ('wet pack') method; group II includes those eyes implanted with American 4-loop Binkhorst IOLs sterilised by the ethylene oxide ('dry pack') method. Group III denotes those eyes with posterior chamber ('dry pack') lenses implanted at the time of extracapsular cataract extraction.

The mean age of the patients in the 3 groups was essentially the same, averaging 72 years. The followup is longer for the 4-loop Binkhorst lenses, up to 95 months for group I. The mean follow-up for the posterior chamber lens group was 12 months, with a range of 3-44 months; patients with less than 3 months' follow-up have been excluded (70 patients). None of those excluded patients is known to have had a complication of cataract/IOL surgery.

Operative complications were similar in the 3 groups and were generally minimal (Table 2 ). In cases complicated by vitreous loss, intraocular lens implantation was precluded. When the hyaloid face remained intact in the presence of extensive posterior capsular rupture, either a 4-loop Binkhorst IOL (8 cases) or an anterior chamber IOL (7 cases) was implanted; these eyes have not been included in this report, and all had 20/40 or better vision following surgery. If a small tear in the posterior capsule developed without vitreous loss, a posterior chamber lens was inserted.

$81 \%$ of all patients undergoing extracapsular surgery had primary posterior capsulotomies (Table 3 ). Of those remaining patients who did not have primary capsulotomy, of those followed up for one year approximately $20 \%$ have shown significant opacification requiring secondary discission.

\section{Results}

In comparison with the experience of patients with European and American manufactured 4-loop lenses, the posterior chamber lens groups showed a statistically significantly reduced incidence of virtually all postoperative complications, including corneal oedema, retinal detachment, and inflammatory problems such as persistent iritis and cystoid macular oedema. With continued long-term follow-up of our cases the 2 4-loop Binkhorst IOL groups have developed a high rate of late-onset corneal oedema (5.5\% in group I and $2 \%$ in group II); the incidence of corneal oedema is less $(0.1 \%)$ in eyes with the

Table 2 Major operative complications

\begin{tabular}{|c|c|c|c|}
\hline & Group I & Group II & Group III \\
\hline Total: & $\begin{array}{l}\text { 4-Loop } \\
\text { ICCE } \\
\text { Wet pack } \\
\text { 200 eyes }\end{array}$ & $\begin{array}{l}\text { 4-Loop } \\
\text { ICCE } \\
\text { Dry pack } \\
\text { 103 eyes }\end{array}$ & $\begin{array}{l}\text { Post. chamber } \\
\text { ECCE } \\
\text { Dry pack } \\
1041 \text { eyes }\end{array}$ \\
\hline \multicolumn{4}{|l|}{ Complication } \\
\hline Vitreous loss & $0(0.0 \%)$ & $2(2 \cdot 0 \%)$ & $1(0 \cdot 1 \%)$ \\
\hline Unplanned ECCE & $5(2 \cdot 5 \%)$ & $2(2 \cdot 0 \%)$ & - \\
\hline $\begin{array}{l}\text { Unintentional tear in posterior capsule } \\
\text { Reated to IOL insertion: rupture of }\end{array}$ & - & - & $15(1 \cdot 4 \%)^{*}$ \\
\hline vitreous face & $2(1 \cdot 0 \%)$ & $2(2 \cdot 0 \%)$ & $2(0 \cdot 2 \%)$ \\
\hline
\end{tabular}

${ }^{*}$ Implanted with 4-loop Binkhorst IOL or anterior chamber IOL. 
Table 3 Noninflammatory postoperative complications

\begin{tabular}{|c|c|c|c|}
\hline & Group I & Group II & Group III \\
\hline Total: & $\begin{array}{l}\text { 4-Loop } \\
\text { ICCE } \\
\text { Wet pack } \\
200 \text { eyes }\end{array}$ & $\begin{array}{l}\text { 4-Loop } \\
\text { ICCE } \\
\text { Dry pack } \\
\text { 103 eyes }\end{array}$ & $\begin{array}{l}\text { Post. chamber } \\
\text { ECCE } \\
\text { Dry pack } \\
1041 \text { eyes }\end{array}$ \\
\hline \multicolumn{4}{|l|}{ Complication } \\
\hline Corneal oedema & $11(5 \cdot 5 \%)$ & $2(2 \cdot 0 \%)$ & $1(0 \cdot 1 \%)$ \\
\hline Retinal detachment & $7(3.5 \%)$ & $2(2 \cdot 0 \%)$ & $9(0.9 \%)$ \\
\hline Subluxation of IOL & $12(6 \cdot 0 \%)$ & $4(4 \cdot 0 \%)$ & $3(0 \cdot 3 \%)$ \\
\hline Pupillary capture & - & - & $5(0.5 \%)$ \\
\hline Opacification of posterior capsule & $=$ & - & $(15-20 \%)^{*}$ \\
\hline $2^{\circ}$ Glaucoma & 0 & $3(3 \cdot 0 \%)$ & $2(0 \cdot 2 \%)$ \\
\hline Sphincter erosion & $2(1.0 \%)$ & $2(2 \cdot 0 \%)$ & 0 \\
\hline
\end{tabular}

${ }^{*} 81 \%$, primary capsulotomy.

American-manufactured posterior chamber lens. Only one case of corneal oedema has been noted in association with posterior chamber lens implantation. Unlike the Binkhorst lens patients, in whom the onset of corneal oedema was delayed, this case of oedema occurred immediately postoperatively and was probably due to inadvertent introduction of some toxic material into the anterior chamber at the time of surgery. (The patient is currently doing well, with 20/30 vision following keratoplasty.)

The onset of corneal oedema in the 4-loop Binkhorst lens groups has been delayed in all cases, and it developed 36 months (mean) following surgery (range, 10-60 months). To our knowledge the corneal oedema in these eyes with iris-fixated lenses was not preceded by any intraoperative complication. All eyes (except 2 with macular degeneration) had $20 / 30$ vision or better before the loss of corneal clarity. Furthermore, subluxation of the IOL was noted in only 3 of 13 cases, and repositioning was achieved pharmacologically. Although an additional $2 \%$ of all Binkhorst lens eyes have shown mild peripheral corneal oedema, vision has been unaffected, and these patients have not been included in the 'corneal oedema' category. The prevalence of persistent postoperative corneal oedema at each 6month period after surgery is shown in Fig. 1. For group I patients followed up longer than 70 months there was a greater than $15 \%$ risk of developing persistent corneal oedema.

With respect to retinal detachment, we cannot state that there was a clinically significant difference in the 3 groups, because of variability in follow-up time

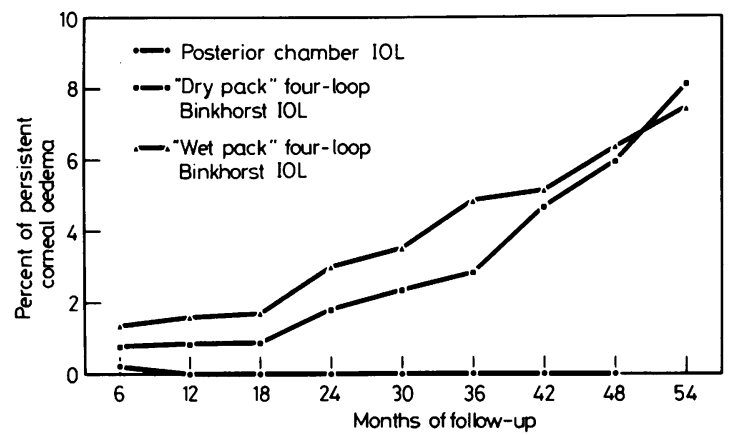

Fig. 1 Prevalence of persistent postoperative corneal oedema at each 6-month period.

Table 4 Inflammatory postoperative complications

\begin{tabular}{llll}
\hline & Group I & Group II & Group III \\
\cline { 2 - 4 } & $4-$ Loop & $4-$ Loop & Post. chamber \\
& ICCE & ICCE & Dry pack \\
Total: & Wet pack & Dry pack & 1041 eyes \\
\hline Complication & 200 eyes & 103 eyes & \\
Endophthalmitis & & & $2(0 \cdot 2 \%)$ \\
Hypopyon & $1(0 \cdot 5 \%)$ & $0(0 \cdot 0 \%)$ & $6(0 \cdot 6 \%)$ \\
Vitritis and papillitis & $3(1.5 \%)$ & $7(7 \cdot 0 \%)$ & $6(0 \cdot 6 \%)$ \\
Persistent iritis & $0(0 \cdot 0 \%)$ & $3(3.0 \%)$ & $6(0 \cdot 6 \%)$ \\
Cystoid macular oedema & $14(7 \cdot 0 \%)$ & $21(20 \%)$ & $23(2 \cdot 3 \%)$
\end{tabular}

${ }^{*}$ Clinical cystoid macular oedema with reduced acuity. 
Table 5 Cystoid macular oedema

\begin{tabular}{|c|c|c|c|}
\hline & Group I & Group II & Group III \\
\hline Total: & $\begin{array}{l}\text { 4-Loop } \\
\text { ICCE } \\
\text { Wet pack } \\
200 \text { eyes }\end{array}$ & $\begin{array}{l}\text { 4-Loop } \\
\text { ICCE } \\
\text { Dry pack } \\
\text { l03 eyes }\end{array}$ & $\begin{array}{l}\text { Post. chamber } \\
\text { ECCE } \\
\text { Dry pack } \\
\text { 104l eyes }\end{array}$ \\
\hline \multicolumn{4}{|l|}{ Macular oedema cases } \\
\hline Total number $\mathrm{CMO}^{*}$ & $20(10 \%)$ & $23(23 \%)$ & $23(2 \cdot 3 \%)$ \\
\hline Persistent CMO & $2(1.0 \%)$ & $10(10 \cdot 0 \%)$ & $3(0 \cdot 3 \%)$ \\
\hline $\begin{array}{l}\text { Onset (median) } \\
\quad \text { (range) }\end{array}$ & $\begin{array}{l}6 \mathrm{mo} \\
(2-26 \mathrm{mo})\end{array}$ & $\begin{array}{l}9 \cdot 5 \mathrm{mo} \\
(2 \cdot 5-55 \mathrm{mo})\end{array}$ & $\begin{array}{l}2 \mathrm{mo} \\
(0 \cdot 5-15 \mathrm{mo})\end{array}$ \\
\hline \multicolumn{4}{|l|}{ Duration (median) } \\
\hline persistent CMO & $35 \mathrm{mo}$ & $29 \mathrm{mo}$ & $5 \cdot 5 \mathrm{mo}$ \\
\hline transient CMO & $12 \mathrm{mo}$ & $9 \mathrm{mo}$ & $2 \cdot 5 \mathrm{mo}$ \\
\hline (range) & $(0 \cdot 5-48 \mathrm{mo})$ & $(2-26 \mathrm{mo})$ & $(1-5 \mathrm{mo})$ \\
\hline Worst vision (mean) & $20 / 60$ & $20 / 100$ & $20 / 70$ \\
\hline \multicolumn{4}{|l|}{ Final vision (mean) } \\
\hline persistent CMO & $20 / 77$ & $20 / 92$ & $20 / 180 \dagger$ \\
\hline transient CMO & $20 / 23$ & $20 / 55$ & $20 / 25$ \\
\hline
\end{tabular}

${ }^{*}$ Clinical CMO with reduced acuity.

† Associated macular degeneration in all 3 cases.

(Table 3). In the posterior chamber lens group 9 patients have had postoperative retinal detachment (mean age $66 \cdot 2$, range $62-75$ ). None of these cases were associated with intraoperative complications, and 6 of 9 had primary capsulotomies, conforming to the distribution of discissions within the total posterior chamber lens population. The range, in terms of onset of detachment, was quite variable (1-17 months). although most occurred approximately one half year postoperatively. Vitreous was noted in the anterior chamber at the time of presentation in 2 cases. Following retinal detachment repair, anatomical success rates have been good (9/9), with retention of excellent visual acuity (mean acuity 20/25), the exception being one patient who had an epiretinal membrane noted preoperatively. Mean follow-up has been 12.5 months (range 5-18 months) and no reoperations have been required.

We have previously reported an increased incidence of postoperative iritis and hypopyon with early American-manufactured 4-loop lenses (probably due to lens contaminants) ${ }^{6}$ it is likely that this inflammation is directly related to the higher incidence of cystoid macular oedema rate found in those cases, as compared to the cystoid macular oedema noted in eyes with European lenses or American posterior chamber lenses. There is a statistically significant difference between all 3 groups, the posterior chamber IOLs being associated with the least cystoid macular oedema, $2 \cdot 3 \%$ (Table 4). In terms of persistent cystoid macular oedema there is no statistically significant difference between the European 4-loop and the posterior chamber lenses, both showing low rates of $1 \%$ and $0.3 \%$ respectively (Table 5).
In the posterior chamber IOL group the median time of onset of cystoid macular oedema was 2 months following surgery, and in those cases that cleared it typically lasted only 2.5 months (range, 0.5-16) - presenting earlier and resolving more quickly than in the groups with Binkhorst lenses (Table 5). The onset of cystoid macular oedema was less than 7 months postoperatively for $95 \%$ of the affected posterior chamber IOL eyes. Follow-up has, of course, been longer for the Binkhorst lens cases, and cystoid macular oedema has appeared as long as 55 months after surgery in some eyes (group II). This has been attributed to the chronic, mild inflammation associated with that lens, and it may be anticipated that additional cases of macular oedema will be seen. With longer follow-up it is apparent that the prevalence of cystoid macular oedema remains higher for the 4-loop Binkhorst cases than for the posterior chamber IOL cases, and this is especially true for the group II Binkhorst lenses (Fig. 2).

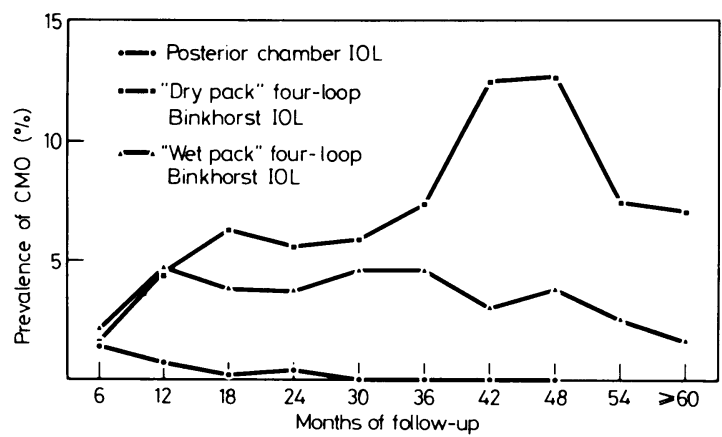

Fig. 2 Prevalence of cystoid macular oedema during each 6-month postoperative period. 
Table 6 Visual acuity results: most recent follow-up

\begin{tabular}{|c|c|c|c|}
\hline & Group I & Group II & Group III \\
\hline Total: & $\begin{array}{l}\text { 4-Loop } \\
\text { ICCE } \\
\text { Wet pack } \\
200 \text { eyes }\end{array}$ & $\begin{array}{l}\text { 4-Loop } \\
\text { ICCE } \\
\text { Dry pack } \\
103 \text { eyes }\end{array}$ & $\begin{array}{l}\text { Post. chamber } \\
\text { ECCE } \\
\text { Dry pack } \\
1041 \text { eyes }\end{array}$ \\
\hline \multicolumn{4}{|l|}{ Visual acuity } \\
\hline $20 / 20$ or better & $99(49 \cdot 5 \%)$ & $49(48 \%)$ & $625(60 \%)$ \\
\hline $20 / 25$ & $27(13.5 \%)$ & $15(15 \%)$ & $187(18 \%)$ \\
\hline $20 / 30$ & $22(11 \%)$ & $14(14 \%)$ & $115(11 \%)$ \\
\hline $20 / 40$ & $11(5 \cdot 5 \%)$ & $8(8 \%)$ & $73(7 \%)$ \\
\hline $20 / 50-20 / 100$ & $27(13.5 \%)$ & $7(7 \%)$ & $21(2 \%)$ \\
\hline $20 / 200$ & $3(1.5 \%)$ & $4(4 \%)$ & $10(1 \%)$ \\
\hline $1 / 420 / 200$ & $11(5 \cdot 5 \%)$ & $6(6 \%)$ & $10(1 \%)$ \\
\hline $20 / 15-20 / 40^{*}$ & 137 of $159^{*}(86 \%)$ & 80 of $93^{*}(86 \%)$ & 918 of $937^{*}(98 \%)$ \\
\hline
\end{tabular}

*Excluding cases with known macular degeneration of amblyopia.

Overall mean worst vision was poorer for eyes with the American-manufactured dry-pack 4-loop Binkhorst IOLs than for the other 2 groups, but the differences were not statistically significant (Table 5). At the time of worst visual acuity, approximately $30 \%$ of cystoid macular oedema cases in all 3 groups, had $20 / 40$ vision or better. Of the cases of transient cystoid macular oedema in the posterior chamber lens group, all eyes except one recovered 20/30 vision. Overall, our clinical impression is that the cystoid macular oedema seen in the extracapsular/posterior chamber lens group is more transient and less severe than in those affected individuals with iris-fixated lenses.

Final vision of the eyes with persistent cystoid macular oedema was worse in the group with the posterior chamber IOL. All 3 cases of persistent cystoid macular oedema in this group had intact posterior capsules. Analysis of those 3 cases shows that 2 of the 3 had macular drusen with several 'window defects' in the pigment epithelium prior to surgery: although they had fluorescein leakage known to be typical of cystoid macular oedema, the leakage may have been present prior to cataract surgery, associated with the macular degeneration. The third eye with persistent cystoid macular oedema had a history of retinal detachment with an internal limiting membrane contracture: fluorescein leakage in a cystoid macular oedema pattern was discovered postoperatively, but it too may have been present prior to cataract removal. Not surprisingly 10 of 23 posterior chamber IOL patients had prior or existing systemic vascular disease or diabetes mellitus, although we could not demonstrate a higher cystoid macular oedema rate in such individuals within the total posterior chamber lens population.

Of those individuals developing cystoid macular oedema, $20(87 \%)$ posterior chamber patients had primary capsulotomies while 3 patients did not have primary discission of the posterior capsule. For our total posterior chamber lens population, the cystoid macular oedema rate (transient and persistent) was the same whether or not capsulotomy was performed. Either an intact posterior capsule or a posterior chamber lens bridging an open capsule could provide a barrier between the vitreous body and the anterior segment, thereby reducing the probability of vitreal contact with the iris and/or the surgical wound.

'Most recent' visual acuities have been analyzed for all IOL groups, although they cannot be directly compared due to variable length of follow-up (Table 6). Nevertheless it is apparent that there has been a progressive loss of vision in eyes receiving the 4-loop Binkhorst IOLs. In part a decrease in vision can be explained by the onset of senile macular degeneration as this population ages. However, $5.5 \%$ of those patients receiving the European Binkhorst lens have developed corneal oedema, and $10 \%$ of those patients receiving the American-manufactured Binkhorst lens have persistent (and probably permanent) cystoid macular oedema. $98 \%$ of those patients receiving a posterior chamber IOL have $20 / 40$ or better vision, excluding those patients with known macular degeneration or amblyopia.

\section{Discussion}

Pupillary supported IOLs have recently become less popular, because of the reported higher rate of cystoid macular oedema. We have attributed this problem in part to the inflammation associated with the etheyleneoxide-sterilised ('dry pack') IOLs used in 1978 and 1979. ${ }^{6}$ Pupillary supported IOLs were being used in the USA in over $50 \%$ of cases at that time, and thus were implicated as the cause of the associated cystoid 
macular oedema. We believe the pupillary supported IOLs do cause more iritis and probably more clinically significant cystoid macular oedema, but the greater problem with pupillary supported IOLs is the high incidence of late-onset corneal oedema. ${ }^{7}$ Therefore we advise caution in the use of these lenses in younger patients. The uveitis, glaucoma, and hyphaema (UGH syndrome) associated with some anterior chamber IOLs has been corrected by better manufacturing techniques. At the Wilmer Institute we have had minimal experience with the use of anterior chamber IOLs, and we do not know whether lateonset corneal oedema or macular oedema will be a problem.

With regard to posterior chamber IOL implantation, we have analysed 4 years of follow-up results. Because of the position of the pseudophakos behind the iris, we do not expect to see late-onset corneal oedema or macular oedema. Since we are not aware of any long-term complications with use of the posterior chamber IOL, patient selection criteria for lens implantation have been relaxed in a gradual fashion.

\section{CONCLUSION}

Results to date are certainly encouraging with respect to our current method of combining extracapsular surgery with posterior chamber lens implantation. The postoperative complication rate appears to be reduced when compared with previous intraocular lens techniques used at the Wilmer Institute.

This work was supported, in part by the Heed Foundation (W.R.F.) and the American Intra-Ocular Implant Society (W.R.F.), in addition to National Eye Institute Grant 5R01-EY0-1202-05 (W.J.S.).

\section{References}

1 Statistics on Blindness in the Model Reporting Area, 1969-1970. US DHEW Publ No (NIH) 73-427: 1973.

2 National Center for Health Statistics. Detailed diagnoses and surgical procedures for patients discharged from short-stay hospitals, United States, 1979. US DHHS Publ No (PHS) 82-12741, Hyattsville, MD: 1982.

3 National Center for Health Statistics. Utilization of short-stay hospitals: annual summary for the United States, 1980. Vital and Health Statistics, Series 13, Number 64, US DHHS Publ No(PHS) 82-1725, Hyattsville, MD: 1982.

4 Stark WJ, Worthen DM, Holladay JT, et al. The FDA report on intraocular lenses. Ophthalmology 1983; 90: 311-7.

5 Stark WJ, Hirst LW, Snip RC, et al. A two-year trial of intraocular lenses at the Wilmer Institute. Am J Ophthalmol 1977; 84: 769-74.

6 Stark WJ, Rosenblum PD, Maumenee AE, et al. Postoperative inflammatory reactions to intraocular lenses sterilized with ethyleneoxide. Ophthalmology 1980; 87: 385-9.

7 Stark WJ, Maumenee AE, Dangel ME, et al. Intraocular lenses: experience at the Wilmer Institute. Ophthalmology 1982; 89: $104-8$. 